\title{
Continuing efficacy of milnacipran following long-term treatment in fibromyalgia: a randomized trial
}

\author{
Daniel J Clauw ${ }^{1 *}$, Philip J Mease ${ }^{2}$, Robert H Palmer ${ }^{3}$, Joel M Trugman ${ }^{3}$ and Yong Wang ${ }^{3}$
}

\begin{abstract}
Introduction: Previous studies of long-term treatment response in fibromyalgia and other chronic pain states have generally been limited to approximately one year, leaving questions about the longer-term durability of response. The purpose of this study was to demonstrate continuing efficacy of milnacipran by characterizing changes in pain and other fibromyalgia symptoms after discontinuing long-term treatment. The mean length of milnacipran treatment at the time of randomized withdrawal was 36.1 months from initial exposure to milnacipran (range, 17.9 to 54.4 months).

Methods: After completing a long-term, open-label, lead-in study of milnacipran (which followed varying periods of exposure in previous studies), adult patients with fibromyalgia entered the four-week open-label period of the current study for evaluation of ongoing treatment response. After the four-week period to confirm new baseline status, 151 patients taking milnacipran $\geq 100 \mathrm{mg} /$ day and reporting $\geq 50 \%$ improvement from pre-milnacipran exposure in Visual Analogue Scale (VAS) pain scores were classified as responders. These responders entered the 12-week, double-blind withdrawal period in which they were randomized 2:1 to continue milnacipran or switched to placebo. The prespecified primary parameter was loss of therapeutic response (LTR), defined as increase in VAS pain score to $<30 \%$ reduction from pre-milnacipran exposure or worsening of fibromyalgia requiring alternative treatment. Adverse events and vital signs were also monitored.
\end{abstract}

Results: Time to LTR was shorter in patients randomized to placebo than in patients continuing milnacipran $(P<0.001)$. Median time to LTR was 56 days with placebo and was not calculable for milnacipran, because less than half of the latter group of patients lost therapeutic response by study end. Additionally, $81 \%$ of patients continuing on milnacipran maintained clinically meaningful pain response $(\geq 30 \%$ improvement from premilnacipran exposure), compared with $58 \%$ of patients switched to placebo (sensitivity analysis $\|_{;} P<0.001$ ). The incidences of treatment-emergent adverse events were $58 \%$ and $47 \%$ for placebo and milnacipran, respectively. Mean decreases in blood pressure and heart rate were found in both groups, with greater decreases for patients switched to placebo.

Conclusions: Continuing efficacy of milnacipran was demonstrated by the loss of effect following withdrawal of treatment in patients who received an average of three years of milnacipran treatment.

Trial registration: ClinicalTrials.gov: NCT01014585

\footnotetext{
* Correspondence: dclauw@med.umich.edu

'University of Michigan Medical School, 24 Frank Lloyd Wright Drive, PO Box

385, Ann Arbor, MI 48106

Full list of author information is available at the end of the article
} 


\section{Introduction}

Fibromyalgia is a complex disorder characterized by chronic widespread pain, fatigue, stiffness, poor sleep, depressed mood and cognitive difficulties [1-3]. On the basis of the 1990 American College of Rheumatology (ACR) classification criteria, which focus on pain and tenderness [4], it has been estimated that fibromyalgia affects $2 \%$ to $4 \%$ of the general population [5,6]. However, in a recent population-based study that used modified ACR 2010 diagnostic criteria [7], which incorporate many of the other hallmark symptoms of fibromyalgia [8], the estimated prevalence was $6.4 \%$. Because ongoing therapy is often required to manage the chronic symptoms of fibromyalgia, demonstration of a medicine's long-term efficacy is of great interest to both clinicians and patients.

Centrally acting analgesics, such as the tricyclic compounds, were investigated once it became clear that the diffuse pain and other symptoms of fibromyalgia were likely due to aberrations in the central nervous system. Preliminary studies with amitriptyline and cyclobenzaprine showed efficacy in patients receiving one to three months of treatment $[9,10]$. These initially promising results were not replicated in subsequent longer-term studies, and tolerability is always an issue when using tricyclic compounds. Tramadol, another centrally acting analgesic that likely acts by largely augmenting serotonergic and noradrenergic activity (along with some weak $\mu$-opioid effects) has also been shown to have shortterm efficacy in patients with fibromyalgia [11-13].

As the pathophysiology of fibromyalgia became better understood, research focused on other centrally acting analgesics that would likely improve this condition [14]. This led to the approval of three medications by the US Food and Drug Administration (FDA) for the management of fibromyalgia: pregabalin, duloxetine and milnacipran. FDA approval of these drugs was based on results from large, randomized, placebo-controlled trials ranging from three to six months in duration [15-17]. In addition to each compound demonstrating efficacy in at least two of these pivotal trials, all three compounds were evaluated in extension studies that ranged from three months to one year in duration [18-21]. The longest fibromyalgia study to date was an open-label trial in which patients received up to 3.25 years of milnacipran after having participated in prior placebo-controlled trials or extension studies [22].

Although treatment benefits were found in the extension studies and the open-label milnacipran study, none included a placebo control group, because placebocontrolled, parallel-group clinical trials are ethically and practically difficult to conduct over long periods of time in patients with chronic pain. Therefore, this randomized withdrawal study was conducted to investigate the effects of discontinuing treatment of fibromyalgia patients who had completed participation in the long-term, open-label milnacipran study [22]. This design provided the opportunity to use a randomized, double-blind, placebocontrolled method to evaluate the long-term efficacy of milnacipran in patients with fibromyalgia.

\section{Materials and methods \\ Design overview}

Enrollment began on 20 November 2009, and the last patient visit was completed on 7 June 2010. The study was conducted at 58 US centers and approved by the institutional review board or ethics committee at each site (Appendix 1, Additional File 1), and complied with Good Clinical Practice guidelines and the Declaration of Helsinki. All patients provided their written informed consent to participate in the study.

\section{Participants}

Eligible patients were adults meeting the 1990 ACR criteria for fibromyalgia [4] who entered directly from a long-term, open-label, flexible-dose, lead-in study in which they received milnacipran $50 \mathrm{mg} /$ day to $200 \mathrm{mg} /$ day for up to 3.25 years [22]. Prior to this lead-in study, patients had received up to 15 months of treatment with milnacipran $100 \mathrm{mg} /$ day or $200 \mathrm{mg} /$ day during double-blind studies [20,21,23-27], resulting in up to 4.5 years of milnacipran exposure prior to entering into the current discontinuation study.

Key exclusion criteria included significant risk of suicide, history of serious psychiatric disorder, substantial alcohol use or abuse, pregnancy or breastfeeding, cardiovascular disease within the past 12 months, mean systolic blood pressure $>180 \mathrm{mmHg}$ or diastolic blood pressure $>110 \mathrm{~mm} \mathrm{Hg}$, uncontrolled narrow-angle glaucoma, active liver disease, severe renal impairment and any other medical disorder that might preclude participation as judged by the principal investigator. Certain pharmacologic agents were prohibited during the study, including monoamine oxidase inhibitors, stimulant medications, anorectic agents, daily opiates, sodium oxybate and anesthetic and/or opiate patches. Although daily opiates were prohibited, intermittent use was allowed as needed, except during the seven days before scheduled study visits.

\section{Randomization and interventions}

The study included four weeks during which the patients receiving the same milnacipran dosage as in the lead-in study ( $25 \mathrm{mg}$ to $100 \mathrm{mg}$ twice daily), twelve weeks with patients randomized to milnacipran or placebo (double-blind) and one week of tapering (doubleblind). After the four-week open-label period, patients receiving a minimum dosage of milnacipran $100 \mathrm{mg} /$ day 
and achieving $\geq 50 \%$ pain improvement from pre-milnacipran exposure (that is, baseline Visual Analogue Scale (VAS) pain score prior to any milnacipran treatment in any study) were classified as responders and randomized $(2: 1)$ to continue milnacipran at the same dosage or were switched to placebo. Pain improvement was assessed using 24-hour recall VAS pain scores (range, 0 = "no pain" to 100 = "worst possible pain"). The 50\% threshold was not selected as a benchmark for clinically meaningful pain reduction, but rather to enrich the population of responders so that loss of response after randomization (that is, $<30 \%$ pain reduction from pre-milnacipran exposure and/or worsening of fibromyalgia requiring alternative treatment) could be measured. Patients not meeting the protocol-defined responder criteria were also randomized and followed in the study. However, because these patients were not the primary focus of the study, their results are not presented in this report.

Randomization codes were generated and securely stored by Forest Research Institute, Inc (Jersey City, NJ, USA). An interactive voice and/or web response system was used to calculate the mean pain intensity score during the last week of the open-label period, to allocate patients to the appropriate responder or nonresponder population and to dispense investigational medications, which were sealed and coded to maintain the doubleblinding.

\section{Assessments}

The primary efficacy parameter was time to loss of therapeutic response (LTR), defined as time from baseline (randomization) to the first double-blind study visit in which a patient had $<30 \%$ reduction in VAS pain from pre-milnacipran exposure or worsening of fibromyalgia requiring alternative treatment, as judged by the study's principal investigator. The $30 \%$ threshold was based on an accepted definition of clinically meaningful pain reduction [28]. Patients completed 24-hour recall VAS pain assessments for seven days before each study visit. Pain intensity was calculated as the weekly average of daily assessments. Three sensitivity analyses were performed to confirm findings from the primary analysis using the following LTR definitions: $(1)<30 \%$ reduction in VAS pain score from pre-milnacipran exposure or withdrawal from the study for any reason, (2) $<30 \%$ reduction in VAS pain score from pre-milnacipran exposure and (3) worsening of fibromyalgia requiring alternative treatment. The second sensitivity analysis was used to determine the percentage of patients who maintained clinically meaningful pain improvements from pre-milnacipran exposure $(\geq 30 \%$ reduction in VAS pain score).

Secondary efficacy parameters included time to worsening based on the Patient Global Impression of
Change (PGIC) and the Multidimensional Assessment of Fatigue (MAF) global fatigue index [29]. Based on a seven-point scale, worsening in PGIC was defined as patients' reporting their overall change in fibromyalgia from randomization as "much worse" or "very much worse" (score 6 or 7). Worsening in MAF was defined as a 10-point increase from randomization in the fatigue global index score $(1=$ "no fatigue" to $50=$ "severe fatigue").

Additional efficacy parameters included time to worsening in Short Form-36 Health Survey (SF-36) Physical Component Summary (PCS) and Mental Component Summary (MCS) scores [30], with worsening defined as a six-point decrease from randomization. Mean score changes from randomization in VAS pain, Brief Pain Inventory (BPI) [31], Revised Fibromyalgia Impact Questionnaire (FIQR) [32], SF-36 PCS and MCS, and Multiple Ability Self-Report Questionnaire (MASQ) [33] were also analyzed.

Adverse events, vital signs and clinical laboratory tests were monitored for safety. Treatment emergent adverse events were defined as adverse events that occurred after the first dose of double-blind treatment or increase in severity during this period. Efficacy and safety assessments were conducted at all study visits with the exception of PGIC, which was assessed at weeks 2, 4, 8 and 12 of the double-blind period.

\section{Statistical analyses}

Assuming that $60 \%$ of the placebo and $35 \%$ of the milnacipran groups would experience LTR by end of the double-blind period, it was estimated that 180 enrolled patients (placebo $=60$ and milnacipran $=120$ ) would be needed to detect a $25 \%$ difference between treatment groups with $90 \%$ power at the two-sided $5 \%$ significance test. The safety population included all randomized patients who received one or more doses of doubleblind treatment. The intent-to-treat population included patients in the safety population who had one or more postrandomization pain assessments. Kaplan-Meier estimates were used to analyze time to LTR and time to worsening based on PGIC, MAF, SF-36 PCS and SF-36 MCS scores, with comparisons between treatment groups analyzed using the logrank test. Hazard ratios (HRs) with 95\% confidence intervals (95\% CIs) were calculated using a Cox proportional hazards model with treatment group as the explanatory variable. Patients who completed the study without experiencing LTR or who withdrew for any reason other than LTR were censored in the primary efficacy analyses.

An analysis of covariance model was used to calculate mean changes from randomization, with treatment group and study center as factors and baseline value as a covariate. Missing data were imputed using the last 
observation carried forward approach. Tests were two-sided performed at the 5\% level of significance. Descriptive statistics were used to analyze changes from randomization in vital signs and clinical laboratory values, with the end of the study defined as the last available assessment in the double-blind period. All analyses were performed using SAS version 9.1.3 software (SAS Institute, Cary, NC, USA).

\section{Results}

\section{Patients}

Of the 340 patients who completed the four-week openlabel period, 151 (44.4\%) were classified as responders and randomized to continue milnacipran $(n=100)$ or switched to placebo $(n=51)$ (Figure 1$)$. Of the patients randomized to continue milnacipran, 75 patients $(75.0 \%)$ completed the study and 31 patients (60.8\%) randomized to placebo completed the study. Most discontinuations during the double-blind period were due to worsening of fibromyalgia requiring alternative treatment, which was one of the LTR definitions used in this study. Two patients randomized to milnacipran discontinued due to an adverse event. One patient randomized to placebo did not receive double-blind treatment and was therefore excluded from safety and efficacy analyses.

Among the 150 patients analyzed for safety and efficacy, demographics and clinical characteristics were similar between treatment groups at randomization (Table 1). In these patients, mean total exposure prior to randomization (that is, total duration of milnacipran treatment in all prior studies and the four-week openlabel period of this study) was 36.1 months (range, 17.9 to 54.4 months). Total duration of milnacipran exposure prior to randomization was as follows (percentage of patients): more than 12 to 24 months $(14 \%)$, more than 24 to 36 months (39\%), more than 36 to 48 months (33\%) and more than 48 to 60 months (14\%).

\section{Efficacy parameters}

Patients discontinuing milnacipran had significantly shorter time to LTR than patients who continued treatment (primary analysis; HR, 0.44 [95\% CI, 0.27 to 0.71 ]; $P<0.001$ ) (Figure 2 and Table 2). Median time to LTR was 56 days for placebo and was not calculable for milnacipran, because $50 \%$ of patients in the latter group did not experience LTR by the end of the study. At the end of the study, $64 \%$ of the patients switched to placebo experienced an LTR compared with $35 \%$ of patients who continued milnacipran. Very similar results were found when LTR was defined as more than $30 \%$ reduction in VAS pain score from pre-milnacipran exposure or withdrawal from the study for any reason (instead of worsening of fibromyalgia requiring alternative treatment) (sensitivity analysis I; HR, 0.46 [95\% CI, 0.29 to
0.74]; $P=0.001)$. In addition, the percentage of patients maintaining $30 \%$ or more pain improvement from premilnacipran exposure was $81 \%$ in the milnacipran group and $58 \%$ in the placebo group (sensitivity analysis II; HR, 0.35 [95\% CI, 0.19 to 0.65 ]; $P<0.001$ ). The only nonsignificant finding was for sensitivity analysis III, which simply defined LTR as worsening of fibromyalgia requiring alternative treatment.

Patients discontinuing milnacipran had a shorter time to worsening than patients continuing treatment in PGIC, MAF global fatigue, SF-36 PCS and SF-36 MCS scores (Table 2), with significant between-group differences for PGIC (HR, 0.36 [95\% CI, 0.20 to 0.63]; $P<$ $0.001)$. In addition, mean least squares changes from randomization indicated greater worsening in VAS pain, BPI average pain, FIQR and SF-36 PCS scores with placebo versus milnacipran, with significant between-group differences observed at all study visits $(P<0.05)$ (Figure $3)$. Patients switched to placebo also had greater worsening from randomization in mental functioning (SF-36 MCS: placebo, -4.64; milnacipran, -2.79) and cognitive difficulties (MASQ total: placebo, +3.43; milnacipran, +2.45 ), although differences between treatment groups were not significant.

\section{Tolerability and safety outcomes}

Among the 357 patients receiving milnacipran during the four-week open-label period, treatment emergent adverse events occurring in $\geq 2.5 \%$ of patients were upper respiratory tract infection (3.4\%), nasopharyngitis (2.5\%) and nausea $(2.5 \%)$. No serious adverse events occurred during this period, and two patients discontinued due to adverse events (one with nausea and one with hypertension). During the double-blind period, $47 \%$ of patients continuing milnacipran and $58 \%$ of patients switched to placebo reported one or more treatment emergent adverse events (Table 3). Adverse events led to premature discontinuation in two patients receiving milnacipran (one with nausea and vomiting and one with increased heart rate and hypertension) and no patients receiving placebo. The only serious adverse event (noncardiac chest pain) was reported in one milnacipran-treated patient. No deaths occurred during the study.

Mean decreases in sitting vital signs were found in both treatment groups during the double-blind period, with greater decreases observed in patients receiving placebo. Mean changes from randomization to the end of the study were as follows: systolic blood pressure (placebo, -1.3 mmHg; milnacipran, $-0.7 \mathrm{mmHg}$ ), diastolic blood pressure (placebo, $-3.4 \mathrm{mmHg}$; milnacipran, -0.8 $\mathrm{mmHg}$ ) and pulse (placebo, -10.6 beats/min; milnacipran, -2.7 beats/min). Potentially clinically significant changes in vital signs were found in one patient receiving milnacipran (heart rate, $\geq 120$ beats $/ \mathrm{min}$ with increase 


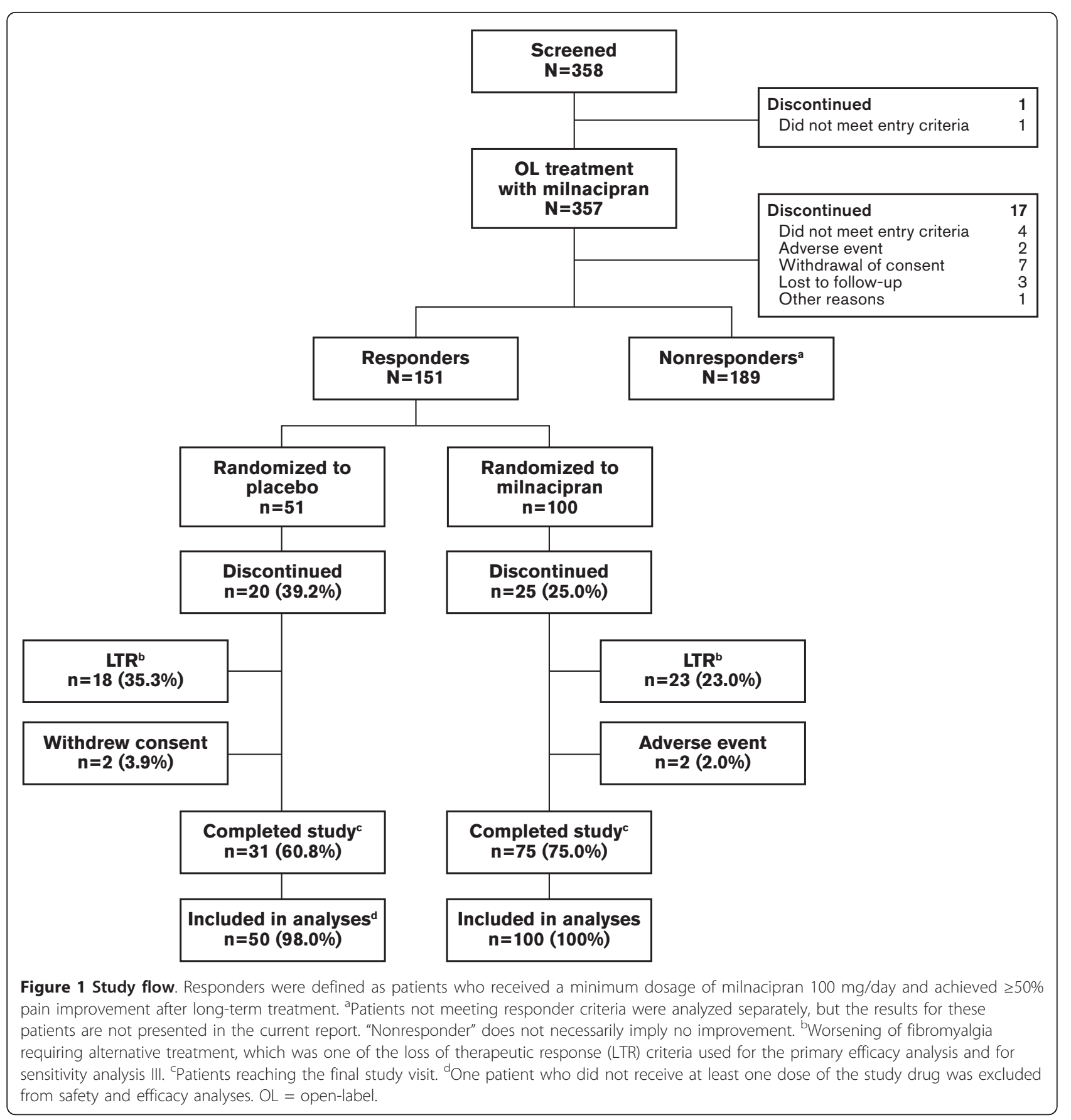

$\geq 20$ beats/min from randomization) and one patient receiving placebo (heart rate, $\leq 50$ beats $/ \mathrm{min}$ with decrease of $\geq 15$ beats/min from randomization). No potentially clinically significant change in laboratory parameters occurred in more than two patients in either treatment group.

\section{Discussion}

Because it can be difficult to conduct long-term, placebocontrolled, parallel-arm studies to assess the efficacy of chronic pain medications, we used a randomized, placebocontrolled, withdrawal design in this trial to evaluate the loss of therapeutic response in patients with fibromyalgia who discontinued long-term treatment with milnacipran. As in other withdrawal studies [34], including the Future Revascularization Evaluation in patients with Diabetes Mellitus: Optimal Management of Multivessel Disease (FREEDOM) study of pregabalin in fibromyalgia [35], the present study focused on a subset of patients who responded to treatment. Although there are differences in 
Table 1 Patient demographics and baseline characteristics ${ }^{a}$

\begin{tabular}{|c|c|c|c|}
\hline Demographics and characteristics & $\begin{array}{l}\text { Placebo } \\
(n=50)\end{array}$ & $\begin{array}{c}\text { Milnacipran } \\
(n=100)\end{array}$ & $\begin{array}{c}\text { Total } \\
(N=150)\end{array}$ \\
\hline Mean age (SD), years & $54.0(8.3)$ & $54.5(9.3)$ & $54.3(9.0)$ \\
\hline Women, $n(\%)$ & $48(96.0)$ & $96(96.0)$ & $144(96.0)$ \\
\hline \multicolumn{4}{|l|}{ Race, $n(\%)$} \\
\hline White & $47(94.0)$ & $96(96.0)$ & $143(95.3)$ \\
\hline Nonwhite & $3(6.0)$ & $4(4.0)$ & $7(4.7)$ \\
\hline Mean weight (SD), $\mathrm{kg}$ & $77.3(16.7)$ & $80.2(14.5)$ & $79.2(15.3)$ \\
\hline Mean body mass index (SD), $\mathrm{kg} / \mathrm{m}^{2}$ & $29.0(6.1)$ & $29.7(5.2)$ & $29.5(5.5)$ \\
\hline Mean SF-36 PCS score (SD) & $41.3(10.2)$ & $41.6(8.4)$ & $41.5(9.0)$ \\
\hline Mean SF-36 MCS score (SD) & $53.6(11.3)$ & $53.6(9.0)$ & $53.6(9.8)$ \\
\hline Mean FIQR total score $(S D)$, range 0 to 100 & $21.4(15.8)$ & $19.4(11.9)$ & $20.1(13.3)$ \\
\hline Mean MAF global fatigue score (SD), range 1 to 50 & $21.4(10.4)$ & $20.7(9.7)$ & $21.0(9.9)$ \\
\hline Mean BPI average pain score (SD), range 0 to 10 & $2.5(1.3)$ & $2.3(1.4)$ & $2.3(1.4)$ \\
\hline Mean VAS pain score (SD), range 0 to 100 & $19.3(11.6)$ & $16.6(9.6)$ & $17.5(10.3)$ \\
\hline Mean VAS pain score (SD), pre-milnacipran exposure ${ }^{b}$ & $66.2(14.7)$ & $65.4(13.0)$ & $65.7(13.6)$ \\
\hline
\end{tabular}

Baseline is defined as the randomization visit in this study. BPI = Brief Pain Inventory; FIQR = Revised Fibromyalgia Impact Questionnaire; MAF =

Multidimensional Assessment of Fatigue; MCS = Mental Component Summary; PCS = Physical Component Summary; SF-36 = Short Form-36 Health Survey; VAS = Visual Analogue Scale. ${ }^{\mathrm{b}}$ Baseline value from lead-in study prior to first milnacipran exposure.

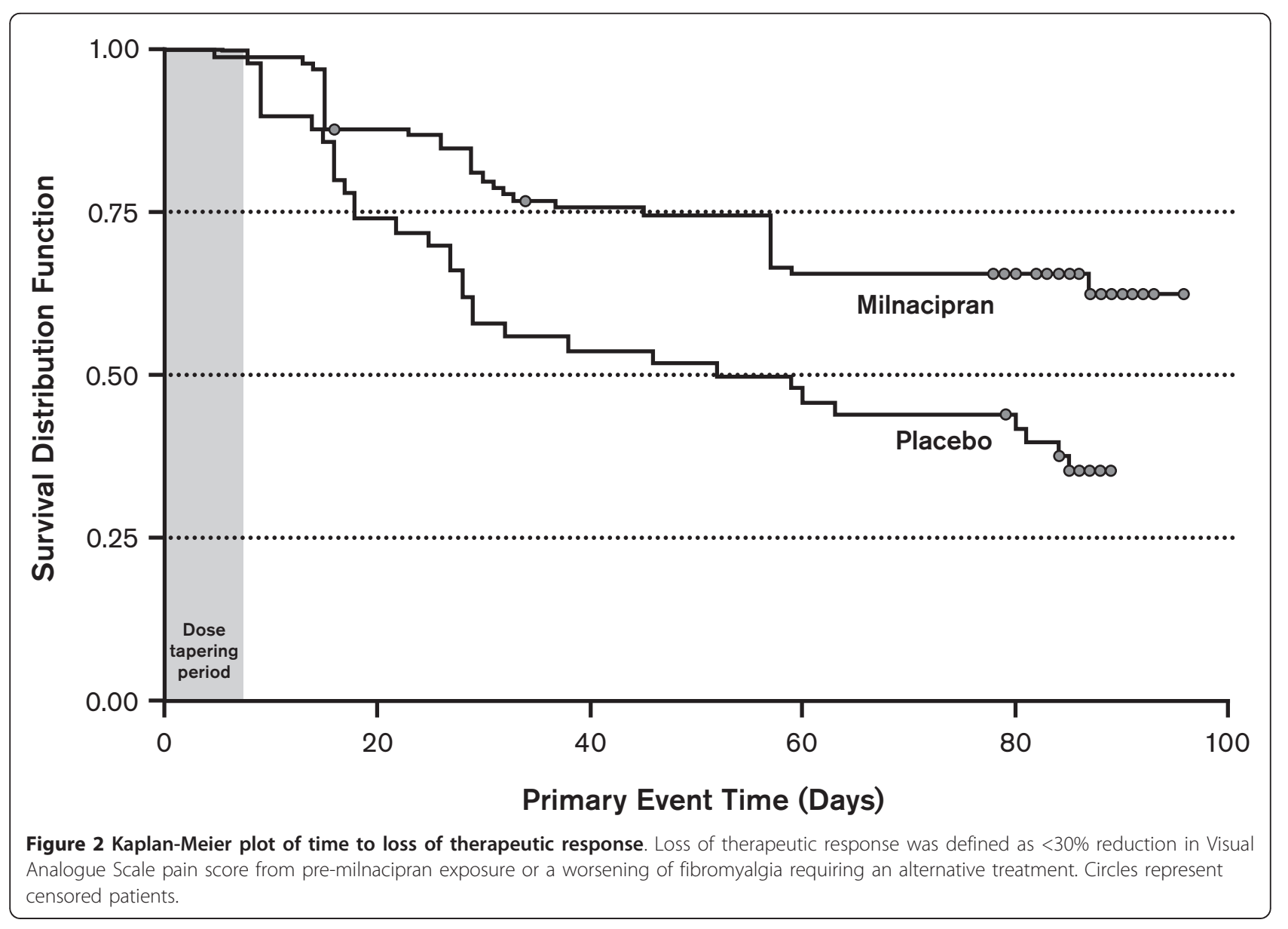


Table 2 Time to loss of therapeutic response ${ }^{a}$

\begin{tabular}{|c|c|c|c|c|c|c|}
\hline \multirow[t]{2}{*}{ Measurement } & \multirow[t]{2}{*}{ Treatment group, $n$} & \multicolumn{2}{|c|}{ Time to LTR, days $(95 \% \mathrm{Cl})^{\mathrm{b}}$} & \multirow{2}{*}{$\begin{array}{l}\text { Hazard ratio } \\
(95 \% \mathrm{Cl})^{\mathrm{c}}\end{array}$} & \multirow[t]{2}{*}{$P$-value ${ }^{d}$} & \multirow{2}{*}{$\begin{array}{c}\text { Patients with LTR at } \\
\text { end of DB } \\
\text { treatment, } n(\%)\end{array}$} \\
\hline & & 25th percentile & 50th percentile & & & \\
\hline \multirow[t]{2}{*}{ Primary analysis } & PBO, 50 & 18 (16 to 29$)$ & 56 (28 to 85$)$ & 0.44 (0.27 to 0.71$)$ & $<0.001$ & $32(64)$ \\
\hline & MLN, 100 & 45 (29 to 59$)$ & NC & & & $35(35)$ \\
\hline \multirow[t]{2}{*}{ Sensitivity analysis I } & PBO, 50 & 18 (16 to 29$)$ & 56 (28 to 85$)$ & 0.46 (0.29 to 0.74$)$ & 0.001 & $32(64)$ \\
\hline & MLN, 100 & 36 (29 to 57$)$ & NC & & & $37(37)$ \\
\hline \multirow[t]{2}{*}{ Sensitivity analysis II } & PBO, 50 & 28 (18 to 63) & 85 (60 to $\mathrm{NL}$ ) & 0.35 (0.19 to 0.65 ) & $<0.001$ & $21(42)$ \\
\hline & MLN, 100 & NC & NC & & & $19(19)$ \\
\hline \multirow[t]{2}{*}{ Sensitivity analysis III } & PBO, 50 & 29 (17 to $\mathrm{NL})$ & NC & 0.59 (0.32 to 1.08$)$ & 0.08 & $18(36)$ \\
\hline & MLN, 100 & 86 (43 to $\mathrm{NL})$ & NC & & & $24(24)$ \\
\hline \multirow[t]{2}{*}{ PGIC } & PBO, 50 & $22(15$ to 31$)$ & 86 (30 to $\mathrm{NL}$ ) & 0.36 (0.20 to 0.63 ) & $<0.001$ & $25(50)$ \\
\hline & MLN, 100 & NC & NC & & & $22(22)$ \\
\hline \multirow[t]{2}{*}{ MAF global fatigue } & PBO, 50 & 18 (16 to 68$)$ & NC & 0.80 (0.46 to 1.38 ) & 0.41 & $20(40)$ \\
\hline & MLN, 100 & 30 (26 to 59 ) & NC & & & $36(36)$ \\
\hline \multirow[t]{2}{*}{ SF-36 PCS } & PBO, 50 & 15 (15 to 22) & 68 (18 to NL) & 0.81 (0.50 to 1.30 ) & 0.36 & $26(52)$ \\
\hline & MLN, 100 & 23 (15 to 33) & 87 (57 to NL) & & & $47(47)$ \\
\hline \multirow[t]{2}{*}{ SF-36 MCS } & PBO, 50 & 28 (16 to 46$)$ & 57 (29 to NL) & 0.74 (0.44 to 1.24$)$ & 0.24 & $23(46)$ \\
\hline & MLN, 100 & 29 (23 to 60$)$ & 90 (85 to $\mathrm{NL})$ & & & $40(40)$ \\
\hline
\end{tabular}

a Loss of therapeutic response was defined as follows: (1) primary analysis: $<30 \%$ reduction in Visual Analogue Scale (VAS) pain score from pre-milnacipran exposure or worsening of fibromyalgia requiring alternative treatment; (2) sensitivity analysis I: $<30 \%$ reduction in VAS pain score from pre-milnacipran exposure or withdrawal from the study for any reason; (3) sensitivity analysis II: $<30 \%$ reduction in VAS pain score from pre-milnacipran exposure; or (4) sensitivity analysis III: worsening of fibromyalgia requiring alternative treatment. DB $=$ double-blind; LTR $=$ loss of therapeutic response; MAF $=$ Multidimensional Assessment of Fatigue; MCS = Mental Component Summary; MLN = milnacipran; NC = not calculable (no patients in quartile); NL = no limit; PBO = placebo; PCS = Physical Component Summary; PGIC = Patient Global Impression of Change; SF-36 = Short Form-36 Health Survey. ${ }^{b}$ Quartiles (that is, 25 th percentile, 50 th percentile) based on Kaplan-Meier estimates. 'Hazard ratio of milnacipran versus placebo based on Cox proportional hazards regression model with treatment group as an explanatory variable. ${ }^{d} P$-values based on logrank comparison between milnacipran and placebo.

design between the present study and FREEDOM, and though it would be improper to make any formal comparison between the two studies, it is of interest that both showed a loss of response in almost two-thirds of patients who were taken off therapy. It is also true that both studies showed a loss of response in almost one-third of patients continuing on therapy-attesting, perhaps, to the underlying variability in the pain of fibromyalgia. The fact that approximately one-third of patients switched to placebo in each study did not lose their therapeutic response is also of interest. Again, this may reflect the natural variability in the disease; in either case, there is sufficient evidence to suggest that these medications had a pharmacologic effect on the fundamental disturbances in pain processing that are characteristic of fibromyalgia [36].

In the current study, we analyzed data from patients who achieved $\geq 50 \%$ pain improvement after receiving 1.5 to 4.5 years (mean, 3 years) of milnacipran treatment in one or more prior clinical trials. Milnacipran dosages had been optimized for each patient entering the withdrawal study ( $50 \mathrm{mg} /$ day to $200 \mathrm{mg} /$ day), although the present analyses were limited to patients receiving at least the minimum recommended dosage of $100 \mathrm{mg} / \mathrm{day}$ [17]. The results of these analyses indicate that the patients classified as responders had experienced clinical benefits during long-term treatment with milnacipran, as evidenced by a shorter time to LTR and greater worsening in symptom severity postrandomization among the patients who were switched to placebo (that is, discontinued treatment) as compared to those who continued milnacipran. For the prespecified primary endpoint, significantly more patients in the placebo group experienced an LTR by the end of study compared to the milnacipran group (64\% vs. $35 \%, P<0.001)$.

The primary endpoint, as well as two of the three sensitivity analyses, included either worsening of fibromyalgia or discontinuation from the study as a definition of LTR. Sensitivity analysis II, however, was based solely on the pain criterion (that is, $<30 \%$ reduction in VAS pain score from pre-milnacipran exposure). The results of this analysis, in conjunction with analyses of mean pain scores at various time points (that is, pre-milnacipran exposure, study randomization and end of study), may provide some important insights about pain responses in patients who had received up to 4.5 years of prior milnacipran treatment. First, notable pain improvements were found in patients who received long-term milnacipran treatment, as indicated by the $73 \%$ decrease in mean VAS pain score from pre-milnacipran exposure $(65.7 \%)$ to randomization (17.5\%) (Table 1 ). Of course, this result was derived from a selected group of responders who elected to continue treatment 


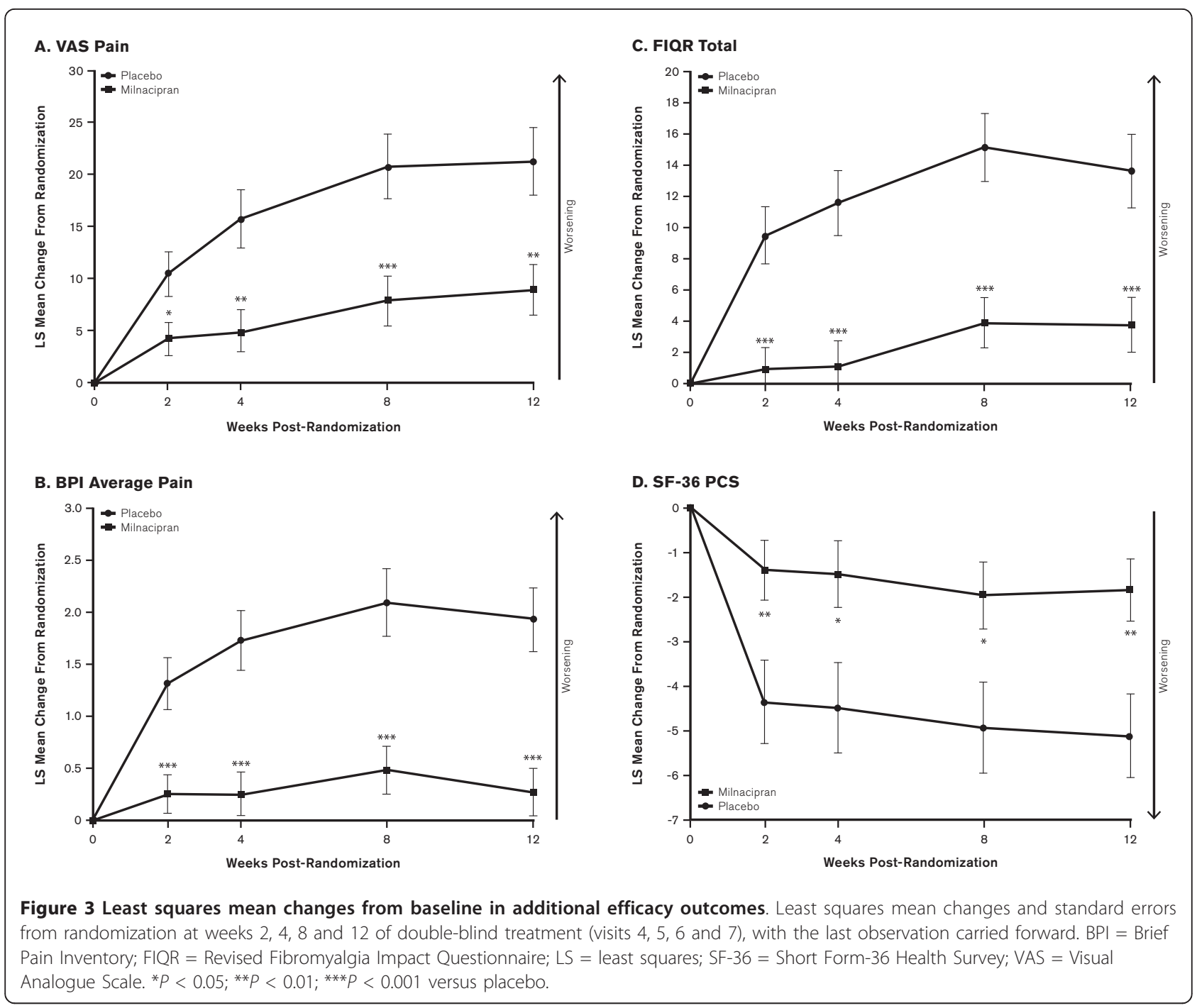

for an extended period of time, and the large mean decrease in pain does not necessarily imply that longterm treatment increases response to milnacipran. Nonetheless, the results from sensitivity analysis II indicate that, after randomization, the percentage of patients maintaining clinically meaningful pain improvement (that is, $>30 \%$ decrease in pain from pre-milnacipran exposure) was higher in the group continuing milnacipran $(81 \%)$ than in the group switched to placebo (58\%) (Table 2). Although mean increases in VAS and BPI pain scores from randomization to the end of the study were observed in both treatment groups, worsening was greater in patients who discontinued milnacipran. There is no definitive explanation for the slight increase in mean pain scores in patients continuing milnacipran, but because randomization was based on achieving a certain level of pain reduction $(\geq 50 \%)$, it is likely that some regression to the mean in pain severity occurred in this group. It is also possible that the results reflect some patients' assumptions that they had been discontinued from active treatment (for example, a "reverse placebo" or nocebo effect) [37].

This study also demonstrated that improvements in global status (PGIC), fibromyalgia severity (FIQR) and physical functioning (SF-36 PCS) occurred in patients receiving long-term milnacipran treatment. A higher percentage of patients discontinuing milnacipran reported feeling "much worse" or "very much worse" since randomization as compared with patients who continued treatment (50\% vs. $22 \%, P<0.001)$. These findings were supported by mean worsening from randomization in FIQR and SF-36 PCS scores, which were significantly worse with placebo than milnacipran at every study visit.

In patients who discontinued treatment, the greatest worsening in mean SF-36 PCS scores occurred between 
Table 3 Incidence of treatment-emergent adverse events ${ }^{a}$

\begin{tabular}{lcc}
\hline Incidence, $\boldsymbol{n}(\%)$ & $\begin{array}{c}\text { Placebo } \\
(\boldsymbol{n}=\mathbf{5 0})\end{array}$ & $\begin{array}{c}\text { Milnacipran } \\
(\boldsymbol{n}=\mathbf{1 0 0})\end{array}$ \\
\hline Patients with $\geq 1$ TEAE & $29(58)$ & $47(47)$ \\
Nausea & $1(2)$ & $4(4)$ \\
Headache & 0 & $4(4)$ \\
Vomiting & $1(2)$ & $4(4)$ \\
Sinusitis & $3(6)$ & $4(4)$ \\
Upper respiratory tract infection & $2(4)$ & $4(4)$ \\
Fatigue & $1(2)$ & $4(4)$ \\
Pain in extremity & $1(2)$ & $4(4)$ \\
Fall & 0 & $4(4)$ \\
Arthralgia & $1(2)$ & $3(3)$ \\
Fibromyalgia & $1(2)$ & $3(3)$ \\
Peripheral edema & $3(6)$ & $2(2)$ \\
Hypothyroidism & $2(4)$ & $1(1)$ \\
Influenza & $2(4)$ & $1(1)$ \\
Irritability & $3(6)$ & 0 \\
Neck pain & $2(4)$ & 0 \\
\hline
\end{tabular}

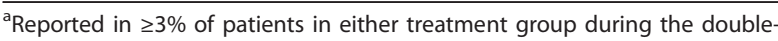
blind period. TEAE = treatment emergent adverse event.

randomization and week 2 , whereas mean VAS pain scores worsened steadily from randomization to week 8 (Figure 3). These results are consistent with findings in an earlier milnacipran study that included 12 weeks of double-blind treatment followed by a 2 -week placebocontrolled discontinuation period [38]. The results from the short discontinuation period in that study also seem to indicate that physical functioning worsens more rapidly than pain after withdrawal of treatment. The reasons for these findings are unknown, but one possible explanation is that the function measures used in previous milnacipran studies were more sensitive than pain measures for detecting loss of response. It is also possible that when fibromyalgia patients experience a decline in physical function after discontinuing treatment, they decrease their activity levels, which in turn prevents them from experiencing increased pain severity. Alternatively, the results may simply indicate that the effects of milnacipran on pain are more persistent than its effects on functioning.

In addition to demonstrating the continuing efficacy of milnacipran, the worsening of pain and other symptoms observed in this withdrawal study confirms the benefit of ongoing treatment in patients with fibromyalgia. Moreover, these results suggest that the underlying pathophysiology of fibromyalgia was been reversed by long-term treatment, which has important implications for our understanding of this disorder-namely, that even a reasonably successful treatment, as demonstrated in this study by the $\geq 50 \%$ pain improvement from pre-milnacipran exposure at randomization, is not sufficient to "cure" individuals with this disorder by somehow resetting pain processing. This finding, combined with the fact that spontaneous remission is very uncommon, suggests that individuals with fibromyalgia who experience significant benefit with initial therapy (at least with this compound) should expect to continue to require long-term treatment.

No unexpected safety issues were observed in this study. Nausea and headache, the most commonly reported treatment emergent adverse events with milnacipran in placebo-controlled trials [25,26,39] and the long-term lead-in study [22], were each observed in $4 \%$ of patients continuing milnacipran in this study. In patients discontinuing treatment, the most common treatment emergent adverse events were sinusitis, peripheral edema and irritability (6\% each with none rated as severe). Of those symptoms, only irritability is commonly associated with the abrupt discontinuation of serotonin and norepinephrine reuptake inhibitors $[16,17,40]$. However, patients in this study were not specifically evaluated for a discontinuation syndrome. Mean increases in blood pressure and heart rate have been reported in milnacipran-treated patients during placebocontrolled trials [17]. The results in the present study suggest that the effects of milnacipran on blood pressure and heart rate do not persist after patients discontinue treatment.

A few limitations should be noted. First, on the basis of the results reported above, no conclusions can be drawn about the effects of discontinuing milnacipran in patients who did not meet the stringent $\geq 50 \%$ pain responder criterion. However, subsequent analyses of this study indicate that patients who had $30 \%$ to $<50 \%$ pain improvement from pre-milnacipran exposure, which indicates clinically meaningful improvement, also experienced loss of therapeutic effect after milnacipran was discontinued [41]. Second, although milnacipran dosages were optimized for each patient entering this withdrawal study (50 mg/day to $200 \mathrm{mg} /$ day), the analyses were designed to evaluate only those patients who received at least $100 \mathrm{mg} /$ day, the recommended minimum dosage [17]. Thus, no conclusions can be drawn regarding the effects of any specific dosage. Third, as has been discussed in other randomized withdrawal studies [34,35], some patients may have suspected that they were on placebo if they experienced a clear worsening of symptoms during the 12-week discontinuation period. Any such unblinding effect may have influenced how patients assessed their pain and other symptoms in this study. Nonetheless, significant differences between milnacipran and placebo were observed.

\section{Conclusions}

In patients who received milnacipran for an average of three years (range, 1.5 to 4.5 years), loss of therapeutic response upon discontinuation of treatment provides 
evidence of long-term efficacy of this medication for the management of fibromyalgia.

\section{Additional material}

\section{Additional file 1: List of Institutional Review Boards and Study} Centers.

\begin{abstract}
Abbreviations
BPI: Brief Pain Inventory; FIQR: Revised Fibromyalgia Impact Questionnaire; LTR: loss of therapeutic response; MAF: Multidimensional Assessment of Fatigue; MASQ: Multiple Ability Self-Report Questionnaire; MCS: Mental Component Summary; PCS: Physical Component Summary; PGIC: Patient Global Impression of Change; SF-36: Short Form-36 Health Survey; VAS: Visual Analogue Scale.
\end{abstract}

\section{Competing interests}

DJC has received grants and research support from Pfizer Inc and Forest Laboratories. He has been a consultant for and has served on advisory boards for Pfizer Inc, Eli Lilly and Co, Forest Laboratories, Inc, Cypress Bioscience, Inc (now Royalty Pharma), Pierre Fabre Pharmaceuticals, UCB and AstraZeneca. PJM has received research and grant funding as well as consultation fees from Forest Laboratories, Inc, Cypress Bioscience, Inc, Eli Lilly and Co, Pfizer Inc, Allergan, Inc, Wyeth Pharmaceuticals, Jazz Pharmaceuticals and Fralex Therapeutics. In addition to being full-time employees of Forest Research Institute, Inc, a wholly owned subsidiary of the study sponsor (Forest Laboratories, Inc), RHP, JMT and YW hold stock in the parent company.

\section{Authors' contributions}

DJC and RHP contributed the design of this study. JMT was the study director. PJM was a principal investigator of the study. YW performed statistical analyses of the data. All authors had full access to the data and participated in the interpretation of study results. All authors were also involved in drafting and revising the manuscript. All authors approved the final manuscript for publication.

\section{Acknowledgements}

The authors thank all investigators and patients who participated in this study. They also acknowledge Mildred Bahn at Prescott Medical Communications Group (Chicago, IL, USA) for medical writing assistance, which was supported by Forest Research Institute, Inc. This study was funded by Forest Laboratories, Inc (Jersey City, NJ, USA). The sponsor and their collaborator, Cypress Bioscience, Inc (San Diego, CA, USA), were involved in study design and statistical analyses of data.

\section{Authors' details}

'University of Michigan Medical School, 24 Frank Lloyd Wright Drive, PO Box 385, Ann Arbor, MI 48106. ${ }^{2}$ Swedish Medical Center and the University of Washington School of Medicine, 1101 Madison Street, Seattle, WA 98104. ${ }^{3}$ Forest Research Institute, Harborside Financial Center, Plaza V, Suite 1900, Jersey City, NJ 07311.

Received: 3 January 2013 Revised: 1 March 2013

Accepted: 16 August 2013 Published: 16 August 2013

\section{References}

1. MacFarlane GJ, Thomas E, Papageorgiou AC, Schollum J, Croft PR,

Silman AJ: The natural history of chronic pain in the community: a better prognosis than in the clinic? J Rheumatol 1996, 23:1617-1620.

2. Bennett RM: Clinical manifestations and diagnosis of fibromyalgia. Rheum Dis Clin North Am 2009, 35:215-232.

3. Arnold LM, Clauw DJ, McCarberg BH, Fibro Collaborative: Improving the recognition and diagnosis of fibromyalgia. Mayo Clin Proc 2011, 86:457-464.

4. Wolfe F, Smythe HA, Yunus MB, Bennett RM, Bombardier C, Goldenberg DL, Tugwell P, Campbell SM, Abeles M, Clark P, Fam AG, Farber SJ, Fiechtner JJ,
Franklin CM, Gatter RA, Hamaty D, Lessard J, Lichtbroun AS, Masi AT, McCain GA, Reynolds WJ, Romano TJ, Russell IJ, Sheon RP: The American College of Rheumatology 1990 Criteria for the Classification of Fibromyalgia: report of the Multicenter Criteria Committee. Arthritis Rheum 1990, 33:160-172.

5. Wolfe F, Ross K, Anderson J, Russell IJ, Hebert L: The prevalence and characteristics of fibromyalgia in the general population. Arthritis Rheum 1995, 38:19-28.

6. White KP, Harth M: Classification, epidemiology, and natural history of fibromyalgia. Curr Pain Headache Rep 2001, 5:320-329.

7. Vincent A, Lahr BD, Wolfe F, Clauw DJ, Whipple MO, Oh TH, Barton DL, St Sauver J: Prevalence of fibromyalgia: a population-based study in Olmsted County, Minnesota, utilizing the Rochester Epidemiology Project. Arthritis Care Res (Hoboken) 2013, 65:786-792.

8. Wolfe F, Clauw DJ, Fitzcharles MA, Goldenberg DL, Häuser W, Katz RS, Mease P, Russell AS, Russell IJ, Winfield JB: Fibromyalgia criteria and severity scales for clinical and epidemiological studies: a modification of the ACR Preliminary Diagnostic Criteria for Fibromyalgia. J Rheumatol 2011, 38:1113-1122.

9. Goldenberg DL, Burckhardt C, Crofford L: Management of fibromyalgia syndrome. JAMA 2004, 292:2388-2395.

10. Carville SF, Arendt-Nielsen S, Bliddal H, Blotman F, Branco JC, Buskila D, Da Silva JA, Danneskiold-Samsøe B, Dincer F, Henriksson C, Henriksson KG, Kosek E, Longley K, McCarthy GM, Perrot S, Puszczewicz M, Sarzi-Puttini P, Silman A, Späth M, Choy EH, EULAR: EULAR evidence-based recommendations for the management of fibromyalgia syndrome. Ann Rheum Dis 2008, 67:536-541.

11. Biasi G, Manca S, Manganelli S, Marcolongo R: Tramadol in the fibromyalgia syndrome: a controlled clinical trial versus placebo. Int $\mathrm{J}$ Clin Pharmacol Res 1998, 18:13-19.

12. Russell IJ, Kamin M, Bennett RM, Schnitzer TJ, Green JA, Katz WA: Efficacy of tramadol in treatment of pain in fibromyalgia. J Clin Rheumatol 2000, 6:250-257.

13. Bennett RM, Kamin M, Karim R, Rosenthal N: Tramadol and acetaminophen combination tablets in the treatment of fibromyalgia pain: a double-blind, randomized, placebo-controlled study. Am J Med 2003, 114:537-545.

14. Schmidt-Wilcke T, Clauw DJ: Fibromyalgia: from pathophysiology to therapy. Nat Rev Rheumatol 2011, 7:518-527.

15. Lyrica (pregabalin) prescribing information. New York: Pfizer Inc; 2012.

16. Cymbalta (duloxetine $\mathrm{HCl}$ ) prescribing information. Indianapolis, IN: Eli Lilly and Co; 2012.

17. Savella (milnacipran $\mathrm{HCl}$ ) prescribing information. St Louis, MO: Forest Pharmaceuticals, Inc; 2012.

18. Arnold LM, Emir B, Murphy TK, Zeiher BG, Pauer L, Scott G, Petersel D: Safety profile and tolerability of up to 1 year of pregabalin treatment in 3 open-label extension studies in patients with fibromyalgia. Clin Ther 2012, 34:1092-1102.

19. Mease PJ, Russell IJ, Kajdasz DK, Wiltse CG, Detke MJ, Wohlreich MM, Walker DJ, Chappell AS: Long-term safety, tolerability, and efficacy of duloxetine in the treatment of fibromyalgia. Semin Arthritis Rheum 2010, 39:454-464.

20. Goldenberg DL, Clauw DJ, Palmer RH, Mease P, Chen W, Gendreau RM: Durability of therapeutic response to milnacipran for fibromyalgia: results of a randomized, double-blind, monotherapy 6-month extension study. Pain Med 2010, 11:180-194.

21. Ferrera R, Palmer R, Chen W, Gendreau R: Improvements in fibromyalgia symptoms are sustained for 1 year with milnacipran treatment: results from 2 double-blind, dose-controlled extension studies [abstract]. J Pain 2009, 10(4 Suppl):S60.

22. Arnold LM, Palmer RH, Ma Y: A 3-year, open-label, flexible-dosing study of milnacipran for the treatment of fibromyalgia. Clin J Pain

23. Gendreau RM, Thorn MD, Gendreau JF, Kranzler JD, Ribeiro S, Gracely RH, Williams DA, Mease PJ, McLean SA, Clauw DJ: Efficacy of milnacipran in patients with fibromyalgia. J Rheumatol 2005, 32:1975-1985.

24. Mease PJ, Clauw DJ, Gendreau RM, Rao SG, Kranzler J, Chen W, Palmer RH: The efficacy and safety of milnacipran for treatment of fibromyalgia: a randomized, double-blind, placebo-controlled trial. J Rheumatol 2009, 36:398-409, A published erratum appears in J Rheumatol 2009, 36:661.

25. Clauw DJ, Mease P, Palmer RH, Gendreau RM, Wang Y: Milnacipran for the treatment of fibromyalgia in adults: a 15-week, multicenter, randomized, 
double-blind, placebo-controlled, multiple-dose clinical trial. Clin Ther 2008, 30:1988-2004, Published errata appear in Clin Ther 2009, 31:446, and Clin Ther 2009 31:1617..

26. Arnold LM, Gendreau RM, Palmer RH, Gendreau JF, Wang Y: Efficacy and safety of milnacipran $100 \mathrm{mg} /$ day in patients with fibromyalgia: results of a randomized, double-blind, placebo-controlled trial. Arthritis Rheum 2010, 62:2745-2756.

27. A study of milnacipran in patients with fibromyalgia: effects on 24-hour ambulatory blood pressure monitoring. [http://clinicaltrials.gov/ct2/show/ NCT00618956].

28. Farrar JT, Young JP Jr, LaMoreaux L, Werth JL, Poole RM: Clinical importance of changes in chronic pain intensity measured on an 11point numerical pain rating scale. Pain 2001, 94:149-158.

29. Belza BL: Comparison of self-reported fatigue in rheumatoid arthritis and controls. J Rheumatol 1995, 22:639-643.

30. Ware JE Jr, Sherbourne CD: The MOS 36-item short-form health survey (SF-36). I. Conceptual framework and item selection. Med Care 1992, 30:473-483.

31. Cleeland CS, Ryan KM: Pain assessment: global use of the Brief Pain Inventory. Ann Acad Med Singapore 1994, 23:129-138.

32. Bennett RM, Friend R, Jones KD, Ward R, Han BK, Ross RL: The Revised Fibromyalgia Impact Questionnaire (FIQR): validation and psychometric properties. Arthritis Res Ther 2009, 11:R120, A published erratum appears in Arthritis Res Ther 2009, 11:415.

33. Seidenberg M, Haltiner A, Taylor MA, Hermann BB, Wyler A: Development and validation of a Multiple Ability Self-Report Questionnaire. J Clin Exp Neuropsychol 1994, 16:93-104.

34. Katz N: Enriched enrollment randomized withdrawal trial designs of analgesics: focus on methodology. Clin J Pain 2009, 25:797-807.

35. Crofford LJ, Mease PJ, Simpson SL, Young JP Jr, Martin SA, Haig GM, Sharma U: Fibromyalgia relapse evaluation and efficacy for durability of meaningful relief (FREEDOM): a 6-month, double-blind, placebocontrolled trial with pregabalin. Pain 2008, 136:419-431.

36. Lee YC, Nassikas NJ, Clauw DJ: The role of the central nervous system in the generation and maintenance of chronic pain in rheumatoid arthritis, osteoarthritis and fibromyalgia. Arthritis Res Ther 2011, 13:211.

37. Okada F: "Reverse placebo effects": anticipation/anxiety at the possibility of receiving placebos. Ann Pharmacother 1992, 26:128.

38. Saxe PA, Arnold LM, Palmer RH, Gendreau RM, Chen W: Short-term (2week) effects of discontinuing milnacipran in patients with fibromyalgia. Curr Med Res Opin 2012, 28:815-821.

39. Mease PJ, Russell IJ, Arnold LM, Florian H, Young JP Jr, Martin SA, Sharma U: A randomized, double-blind, placebo-controlled, phase III trial of pregabalin in the treatment of patients with fibromyalgia. J Rheumatol 2008, 35:502-514.

40. Pristiq (desvenlafaxine) prescribing information. Philadelphia: Wyeth Pharmaceuticals Inc; 2011.

41. Clauw DJ, Mease P, Palmer RH, Trugman JM, Ma Y: Efficacy of long-term milnacipran treatment in patients meeting different thresholds of clinically relevant pain relief: subgroup analysis of a double-blind, placebo-controlled, discontinuation study [abstract]. Arthritis Rheum 2012, 64(10 Suppl):S417.

doi:10.1186/ar4268

Cite this article as: Clauw et al:: Continuing efficacy of milnacipran

following long-term treatment in fibromyalgia: a randomized trial. Arthritis Research \& Therapy 2013 15:R88.

\section{Submit your next manuscript to BioMed Central and take full advantage of:}

- Convenient online submission

- Thorough peer review

- No space constraints or color figure charges

- Immediate publication on acceptance

- Inclusion in PubMed, CAS, Scopus and Google Scholar

- Research which is freely available for redistribution

Submit your manuscript at www.biomedcentral.com/submit 